\title{
Peripartum Cardiomyopathy: The Unknown is Known
}

\author{
Prasanna Karthik Suthakaran', Jasima Nilofer ${ }^{2}$, Kothai Gnanamoorthy ${ }^{3}$, Mohammed Idhrees ${ }^{4 *}$ \\ 'Professor, Department of General Medicine, Saveetha Medical College Hospital, Chennai, India \\ ${ }^{2}$ Department of Pathology, Sree Balaji Medical College and Hospital, Chrompet, Chennai \\ ${ }^{3}$ Associate Professor, Department of General Medicine, ESIC Medical College and PGIMSR, India \\ ${ }^{4}$ Institute of Cardiac and Aortic Disorders (ICAD), SRM Institutes for Medical Science (SIMS Hospital), Chennai, India
}

Article Info

\section{Article Notes}

Received: August 16, 2020

Accepted: October 14, 2020

\section{${ }^{*}$ Correspondence:}

Dr. A. Mohammed Idhrees MCh, FAIS, Cardio Thoracic and Vascular Surgeon, Institute of Cardiac and Aortic Disorders, SRM Institutes for Medical Science (SIMS Hospitals),

Chennai, India - 600 026; Telephone No: +919962268787; Email: a.m.idhrees@gmail.com.

(c) 2020 Idhrees M. This article is distributed under the terms of the Creative Commons Attribution 4.0 International License.

\section{Keywords:}

Cardiomyopathy

Pregnancy

Postpartum

Heart failure

\section{Abstract}

Peripartum cardiomyopathy is a idiopathy cardiomyopathy associated with heart failure towards the end of pregnancy or in the postpartum period. Various mechanisms like myocarditis, autoimmune response to pregnancy, viral infections, selenium deficiency, oxidative stress and prolonged tocolysis have been proposed as the etiology. The most common presentation is acute heart failure occurring usually within a few weeks after delivery with patients developing exertional breathlessness, orthopnea and paroxysmal nocturnal dyspnea. Cardiac Magnetic Resonance Imaging is useful in accurate measurement of chamber volumes and global and segmental myocardial function. The gold standard test for diagnosis of peripartum cardiomyopathy is Endomyocardial biopsy with the histological Dallas criteria. Most of these postpartum patients are managed medically. The risk of peripartum cardiomyopathy increases with increasing parity and outcomes in subsequent pregnancies was poor.

\section{Introduction}

The postpartum period of pregnancy is known to have many complications by itself and the dreaded one among it by cardiologists and obstetricians alike is postpartum cardiomyopathy. The term peripartum cardiomyopathy is a better description of the condition. It has been defined as idiopathic cardiomyopathy frequently presenting with heart failure secondary to LV systolic dysfunction (LVEF $<45 \%$ ) towards the end of pregnancy or in the months following delivery, if no other cause of heart failure is found ${ }^{1}$. The first report of such a distinct clinical entity was made by Gouley et al in 1937 and later many authors have described the condition in $\operatorname{detail}^{2-5}$.

\section{Epidemiology}

In view of the exclusionary nature of the diagnosis of the disease and a considerable presence of other cardiac changes in pregnancy mimicking this disease, the exact incidence of the disease is difficult to identify. However the incidence in various populations has been reported to vary. It has been reported as low as 1:100 in some parts of Africa, 1:299 in Haiti and 1:2229 in United States ${ }^{6}$.

\section{Pathogenesis}

The exact reasons behind the pathogenesis of this disease is not clear. Various mechanisms like myocarditis, autoimmune response to pregnancy, viral infections, selenium deficiency, oxidative stress and prolonged tocolysis have been proposed ${ }^{6}$. 
It has been showed that during pregnancy, the hormonal changes lead to an imbalance in oxidative stress which leads to cleavage of Prolactin in to an active 16 - kDa sub fragment by Cathepsin D. This sub fragment has been demonstrated to up regulate the expression of microRNA 146a (miR -146a) which leads to suppression of angiogenesis ${ }^{7}$. Also the blocking of the action of this miR -146a lead to attenuation of the cardiomyopathy features in a mice model ${ }^{8}$.

Viral infections like Parvovirus B19, Coxsackie, Adenovirus, Epstein Barr Virus have been proposed to be the trigger for the development of peripartum cardiomyopathy. The infection may cause direct virus mediated myocardial damage leading to fulminant heart failure or may cause infiltration of the myocardium with the immune response cells like Natural killer cells and macrophages leading to the production of pro inflammatory cytokines like tumour necrosis factor- $\alpha$ (TNF $\alpha$ ), Interleukin-1 (IL - 1) which lead to fibrosis and cardiac dilatation and heart failure 9 . Bultmann et al and Kuhl et al have shown demonstrable evidence to propose a link between the viral infection and the development of peripartum cardiomyopathy ${ }^{10,11}$. Bachmaier et al showed that murine heart muscle-specific alpha myosin heavy chain that has sequence homology to the outer membrane proteins of Chlamydia and thereby infection with Chlamydiae species may predispose to development of Peripartum Cardiomyopathy ${ }^{12}$.

Ansari et al showed that the presence of fetal cells (microchimerism) in maternal circulation triggered an autoimmune response which could lead to the development of autoimmune myocarditis in these patients ${ }^{13}$. This mechanism is further strengthened by evidence from Sliwa et al who showed increased levels of pro inflammatory cytokines and Fas/Apo-1,an apoptotic marker, in newly diagnosed women with peripartum cardiomyopathy ${ }^{14}$.

Morales et al and van Spaendonck-Zwarts et al showed some of the earliest evidence of the inherited nature of this disease and that it shared some of the genetic features with idiopathic dilated cardiomyopathy ${ }^{15,16}$. Morales et al showed mutations in MYH7, SCN5A, PSEN2 and MYBPC3 genes while van Spaendonck-Zwarts et al showed changes in the gene encoding cardiac troponin C (TNNC1). Herman et al identified that truncating mutations in the TTN gene encoding the sarcomere protein titin lead to the development of idiopathic dilated cardiomyopathy ${ }^{17}$. This was further established by Ware et al who demonstrated shared genetic abnormalities in patients with peripartum cardiomyopathy and idiopathic dilated cardiomyopathies. Most of the patients had a truncating mutation in the TTN gene, mostly in the titin A - band ${ }^{18}$.

\section{Histopathology}

Though in the present era, many a times the diagnosis are confirmed on clinical examination and non-invasive imaging, the routine light microscopic evaluation of endomyocardial biopsy (EMB) remains the gold standard for the diagnosis of myocarditis, till date. EMB is used infrequently and in upto $30 \%$ of patients with biopsyproven myocarditis, progression to dilated cardiomyopathy (DCM) can occur and is associated with a poor prognosis ${ }^{44}$. The biopsy size usually ranges between 0.5 and $2 \mathrm{~mm}$ and should include endomyocardial tissue rather than scarred tissue and serial level sections are taken from the same ${ }^{19}$. Biopsies performed within weeks of onset of symptoms have a higher yield than those taken when symptoms have been longstanding. The inflammatory process myocarditis is histologically represented by the presence of two major components, in accordance with the Dallas criteria (1986) - myocardial injury, represented by non-ischemic myocyte necrosis and the presence of interstitial leukocytic infiltrates ${ }^{20}$. Specifically, more than 14 lymphocytes $/ \mathrm{mm}^{2}$ and up to 4 macrophages $/ \mathrm{mm}^{2}$ is required for designation as myocarditis. According to the etiological agent which could either be a secondary inflammatory reaction to an infectious agent (mostly commonly viral) or a primary autoimmune like reaction, the microscopic picture mildly varies. The perinatal women are most susceptible to the development of acute viral myocarditis wherein lymphocytic infiltrates predominate, often more than 50 lymphoid cells $/ \mathrm{mm}^{2}$ with associated macrophages. The amount of inflammation ranges from mild, moderate to severe with its distribution being focal, confluent or diffuse, respectively. This parenchymal infiltration causes myocardial damage is characterized by widespread sarcolemmal fraying and myocyte degeneration/necrosis, and clearly, larger degree of myocyte damage will likely have a poorer prognostic outcome ${ }^{21}$. Rarely, some acute cases have classic viral inclusions within the myocytes.

The interstitial compartment should also be noted for presence of edema and the quantitation of the degree of fibrosis, for which elastic van Gieson stain (for elastic and connective tissue) is employed in addition to the routine H\&E stain. Other inflammatory causes of eosinophilic or granulomatous types are a less common occurrence. In atherosclerosis of the coronary arteries, a considerable amount of adventitial lymphocytic aggregates is noted. This can spill a short way into myocardial tissues and is important not to over-interpret such phenomena, particularly on small samples.

\section{Clinical Features}

The most common presentation is acute heart failure occurring usually within a few weeks after delivery. Patients develop exertional breathlessness, orthopnea and paroxysmal nocturnal dyspnea. These patients can also develop a displaced apical impulse which may be hypodynamic and a S3 gallop rhythm indicating left 
ventricular failure ${ }^{14,22,23}$. Some patients can present chest pain indicating the presence of an acute myocardial infarction like picture or pericarditis ${ }^{24}$. The inflamed myocardium may also lead to conduction abnormalities or arrhythmias in these patients ${ }^{9}$.

In patients with a reduced Ejection Fraction, left ventricular thrombus formation is very common and it can lead to peripheral embolization and the initial presentation may be of the embolization itself ${ }^{14,25,26}$.

\section{Investigations}

Electrocardiographic abnormalities are common in these patients with evidence of left ventricular hypertrophy and ST segment abnormalities being found in most patients ${ }^{27}$. Echocardiogram shows depressed left ventricular contractility and reduced ejection fraction.

Cardiac biomarkers have been extensively studied in multiple studies among patients with peripartum cardiomyopathy. Brain Natriuretic Peptide (BNP) levels are elevated in patients with heart failure due to many causes and is not specific for peripartum cardiomyopathy. But it remains the only one currently in use due to its availability $^{28}$.

MicroRNA - 146a levels can be used to overcome this lack of specificity of BNP as its levels are usually elevated and can be used as a diagnostic marker along with elevated levels of Prolactin and Cathepsin $\mathrm{D}^{29,30}$. Levels of soluble fms-like tyrosine kinase-1 (sFlt1) have been shown to be elevated and levels of relaxin -2 have been shown to be decreased in patients having peripartum cardiomyopathy ${ }^{31}$. However their natural variations during pregnancy and the postpartum period have made their use as diagnostic markers a challenge. Serum Fas/ Apo1 levels measured at patient presentation were not able to predict improvement of cardiac function after 6 months but was useful in predicting mortality in such patients $^{32}$.

Cardiac Magnetic Resonance imaging (cMR) is useful in accurate measurement of chamber volumes and global and segmental myocardial function. It is also has a higher sensitivity than echocardiography to identify left ventricular thrombus ${ }^{33}$. The use of cMR can reduce the need for endomyocardial biopsy as it is able to identify at least $80 \%$ of patients accurately ${ }^{34}$. Using Gadolinium based contrast agents, can help differentiate between myocarditis and ischemia ${ }^{35}$.

The gold standard test for diagnosis of peripartum cardiomyopathy is Endomyocardial biopsy with the histological Dallas criteria ${ }^{16}$. The use of cMR to guide the area for biopsy is better than a blind biopsy to clinch the diagnosis ${ }^{36}$. However the use of endomyocardial biopsy during cardiomyopathy has become controversial with recommendations for and against the procedure ${ }^{37,38}$. More recent studies have shown the potential of Cardiac Magnetic Resonance imaging in the accurate diagnosis of peripartum cardiomyopathy and hence may be the new gold standard for diagnosis of this condition ${ }^{39}$.

\section{Treatment}

The management of such patients is according to the guidelines issued for management of heart disease during pregnancy by the American College of Cardiology and European Society of Cardiology. Use of ACE inhibitors, ARBs and Diuretics are contraindicated in Antenatal patients. Hence they have to be managed with other vasodilator drugs like hydralazine and beta blockers.

A multi-disciplinary team approach (cardiologist, obstetrician, anaesthesiologist, neonatologist and intensive care physician) is needed for the management of patients with peripartum cardiomyopathy. Safe delivery of the foetus by vaginal delivery in mildly symptomatic patients is preferred while caesarean section may be needed in sick patients.

Postpartum management depends on the presentation. Acute Heart failure management includes the use of diuretics, inotropes, non invasive ventilation and Bromocriptine. In patients developing refractory Heart failure, LV assist devices and Implantable Cardioverted Defibrillator devices have been recommended to improve outcomes.

Bromocriptine has shown good response by its antagonist action against Prolactin secretion. Multiple studies have confirmed this beneficial outcome in patients with peripartum cardiomyopathy ${ }^{40,41}$. The current management of patients is the BOARD (Bromocriptine, Oral heart failure therapies, Anticoagulation, vasoRelaxing agents, and Diuretics) regime ${ }^{42}$.

\section{Long Term Outcomes}

The risk of peripartum cardiomyopathy increases with increasing parity and outcomes in subsequent pregnancies was poor ${ }^{43}$. It is necessary to identify high risk patients especially those who do not recover LV function and advise them about contraceptive methods which reduces the morbidity and mortality.

\section{References}

1. Sliwa K, Hilfiker-Kleiner D, Petrie MC, et al. Heart Failure Association of the European Society of Cardiology Working Group on Peripartum Cardiomyopathy. Current state of knowledge on aetiology, diagnosis, management, and therapy of peripartum cardiomyopathy: a position statement from the Heart Failure Association of the European Society of Cardiology Working Group on peripartum cardiomyopathy. Eur J Heart Fail. 2010; 12: 767-778.

2. Gouley BA, McMillan TM, Bellet S. Idiopathic myocardial degeneration associated with pregnancy and especially the puerperium. Am J Med Sci. 1937; 19: 185-99. 
3. Demakis JG, Rahimtoola SH, Sutton GC, et al. Natural course of peripartum cardiomyopathy. Circulation. 1971; 44: 1053-61.

4. Sanderson JE, Adesanya CO, Anjorin FI, et al. Postpartum cardiac failureheart failure due to volume overload? Am Heart J. 1979; 97: 613-21.

5. Desai D, Moodley J, Naidoo D. Peripartum cardiomyopathy: experiences at King Edward VIII Hospital, Durban, South Africa and a review of the literature. Trop Doct. 1995; 25: 118-23.

6. Hilfiker-Kleiner D, Haghikia A, Nonhoff J, et al. Peripartum cardiomyopathy: current management and future perspectives, Eur Heart J. 2015; 36(18): 1090-7. https://doi.org/10.1093/eurheartj/ ehv009

7. Patten IS, Rana S, Shahul S, et al. Cardiac angiogenic imbalance leads to peripartum cardiomyopathy. Nature. 2012; 485: 333-338.

8. Halkein J, Tabruyn SP, Ricke-Hoch M, et al. MicroRNA-146a is a therapeutic target and biomarker for peripartum cardiomyopathy. J Clin Invest. 2013; 123(5): 2143-2154. doi:10.1172/JCI64365

9. Ilic MD, Simonovic D. Peripartum Myocarditis. In Milei J, Ambrosio G. Diagnosis and Treatment of Myocarditis. doi: 10.5772/54778

10. Bultmann BD, Klingel K, Nabauer M, et al. High prevalence of viral genomes and inflammation in peripartum cardiomyopathy. Am J Obstet Gynecol. 2005; 193: 363-65.

11. Kuhl U, Pauschinger M, Seeberg B, et al. Viral persistence in the myocardium is associated with progressive cardiac dysfunction. Circulation. 2005; 112: 1965-1970.

12. Bachmaier K, Neu N, de la Maza LM, et al. Chlamydia infections and heart disease linked through antigenic mimicry. Science. 1999; 283 1335-9.

13. Ansari AA, Fett JD, Carraway RE, et al. Autoimmune mechanisms as the basis for human peripartum cardiomyopathy. Clin Rev Allergy Immunol. 2002; 23: 301-324.

14. Sliwa K, Skudicky D, Bergemann A, et al. Peripartum cardiomyopathy: analysis of clinical outcome, left ventricular function, plasma levels of cytokines and Fas/Apo-1. J Am Coll Cardiol. 2000; 35: 701-705.

15. Morales A, Painter T, Li R, et al. Rare Variant Mutations in PregnancyAssociated or

16. Peripartum Cardiomyopathy. Circulation. 2010; 121: 2176-82.

17. van Spaendonck-Zwarts KY, van Tintelen JP, van Veldhuisen DJ, et al. Peripartum Cardiomyopathy as a Part of Familial Dilated Cardiomyopathy. Circulation. 2010; 121: 2169-75.

18. Herman DS, Lam L, Taylor MRG, et al. Truncations of Titin Causing Dilated Cardiomyopathy. N Engl J Med. 2012; 366: 619-28.

19. Ware JS, Li J, Mazaika E, et al. Shared Genetic Predisposition in Peripartum and Dilated Cardiomyopathies. N Engl J Med. 2016; 374: 233-41.

20. Baandrup U, Florio RA, Olsen EGJ. Do endomyocardial biopsies represent the morphology of the rest of the myocardium? Eur Heart J. 1982; 1: 171-8.

21. Aretz HT, Billingham ME, Edwards WD, et al. Myocarditis: histopathologic definition and classification. Am J Cardiovasc Pathol. 1987; 1: 3-14.

22. Magnani JW, Danik HJS, Dec GW, et al. Survival in biopsy-proven myocarditis: a long-term retrospective analysis of the histopathologic, clinical, and hemodynamic predictors. Am Heart J. 2006; 151: $463-70$

23. Fett JD, Carraway RD, Dowell DL, et al. Peripartum cardiomyopathy in the Hospital Albert Schweitzer District of Haiti. Am J Obstet Gynecol. 2002; 186: 1005-10.
24. Desai D, Moodley J, Naidoo D. Peripartum cardiomyopathy: experiences at King Edward VIII Hospital, Durban, South Africa and a review of the literature. Trop Doct. 1995; 25: 118-23.

25. Dickfield T, Gagliardi JP, Marcos J, et al. Peripartum cardiomyopathy presenting as an acute myocardial infarction. Mayo Clinic Proc. 2002; 77: 500-501.

26. Isezua SA, Njoku CH, Airede L, et al. Case report: acute limb ischaemia and gangrene associated with peripartum cardiomyopathy. Niger Postgrad Med J. 2005; 12: 237-240.

27. Gagne PJ, Newman JB, Muhs BE. Ischemia due to peripartum cardiomyopathy threatening loss of a leg. Cardiol Young. 2003; 13 209-211.

28. Sliwa K, Fett J, Elkayam U. Peripartum cardiomyopathy. Lancet. 2006; 368:P687-693

29. Azibani F, Sliwa K. Peripartum Cardiomyopathy: an Update. Curr Heart Fail Rep. 2018; 15(5): 297-306. doi:10.1007/s11897-018-0404-x

30. Haghikia A, Podewski E, Libhaber E, et al. Phenotyping and outcome on contemporary management in a German cohort of patients with peripartum cardiomyopathy. Basic Res Cardiol. 2013; 108(4): 366.

31. Halkein J, Tabruyn SP, Ricke-Hoch M, et al. MicroRNA-146a is a therapeutic target and biomarker for peripartum cardiomyopathy. J Clin Invest. 2013; 123(5): 2143-2154

32. Damp J, Givertz MM, Semigran M, et al. Relaxin-2 and soluble Flt1 levels in peripartum cardiomyopathy: results of the multicenter IPAC study. JACC Heart Fail. 2016; 4(5): 380-8. 10.1016/j.jchf.2016.01.004.

33. Sliwa K, Skudicky D, Bergemann A, et al. Peripartum cardiomyopathy: analysis of clinical outcome, left ventricular function, plasma levels of cytokines and Fas/APO-1. J Am Coll Cardiol. 2000; 35(3): 701-705.

34. Mouquet F, Lions C, de Groote $\mathrm{P}$, et al. Characterisation of peripartum cardiomyopathy by cardiac magnetic resonance imaging. Eur Radiol. 2008; 18: 2765-69.

35. Baccouche H, Mahrholdt H, Meinhardt G, et al. Diagnostic synergy of non-invasive cardiovascular magnetic resonance and invasive endomyocardial biopsy in troponin positive patients without coronary artery disease. Eur Heart J. 2009; 30: 2869-79.

36. Laissy JP, Hyafil F, Feldman LJ, et al. Differentiating acute myocardial infarction from myocarditis: diagnostic value of early- and delayedperfusion cardiac MR imaging. Radiology. 2005; 237: 75-82.

37. Leurent G, Baruteau AE, Larralde A, et al. Contribution of cardiac MRI in the comprehension of peripartum cardiomyopathy pathogenesis. Int J Cardiol. 2009; 132: 91-3.

38. Cooper LT, Baughman KL, Feldman AM, et al. The role of endomyocardial biopsy in the management of cardiovascular disease: a scientific statement from the American Heart Association, the American College of Cardiology, and the European Society of Cardiology. Endorsed by the Heart Failure Society of America and the Heart Failure Association of the European Society of Cardiology. Eur Heart J 2007; 28: 3076-93.

39. Midei MG, DeMent SH, Feldman AM, et al. Peripartum myocarditis and cardiomyopathy. Circulation. 1990; 81: 922-28.

40. Liang $\mathrm{Y}, \mathrm{Xu} \mathrm{Y}, \mathrm{Li} \mathrm{W}$, et al. Left ventricular function recovery in peripartum cardiomyopathy: a cardiovascular magnetic resonance study by myocardial T1 and T2 mapping. J Cardiovasc Magn Reson. 2020; 22: 2. https://doi.org/10.1186/s12968-019-0590-z

41. Hilfiker-Kleiner D, Haghikia A, Berliner D, et al. Bromocriptine for the treatment of peripartum cardiomyopathy: a multicentre randomized study. Eur Heart J. 2017; 38(35): 2671-9.

42. Sliwa K, Blauwet L, Tibazarwa K, et al. Evaluation of bromocriptine in the treatment of acute severe peripartum cardiomyopathy: a proofof-concept pilot study. Circulation. 2010; 121(13): 1465-73. 
43. Arrigo M, Blet A, Mebazaa A. Bromocriptine for the treatment of peripartum cardiomyopathy: welcome on BOARD. Eur Heart J. 2017; 38(35): 2680-2.

44. Elkayam U, Padmini P, Tummala P, et al. Maternal and fetal outcomes of subsequent pregnancies in women with peripartum cardiomyopathy. N Engl J Med. 2001; 344: 1567-1571.

45. Hazebroek MR, Everaerts K, Heymans S. Diagnostic approach of myocarditis: strike the golden mean. Neth Heart J. 2014; 22: 80-84. 